\title{
Improvements To The E-Learning Environment: Meeting Student Needs
}

Janet L. Foster, Southeastern Louisiana University, USA

Holly A. Syrdal, Southeastern Louisiana University, USA

\begin{abstract}
Universities are changing delivery methods for courses in order to meet the demands of today's college students. The increasing usage of internet-based courses has significant implications for institutions of higher education. With a goal of expanding enrollment, many are interested in delivering online instruction. At the same time, the proliferation of internet courses leads to questions concerning the quality of online learning. This study focuses on students' perceptions of internet-based courses and the reasons students take such courses. Recommendations to deliver quality learning experiences in the virtual classroom are discerned.
\end{abstract}

\section{INTRODUCTION}

hile internet-based (also called web-based) courses are a relatively recent development in higher education, the concept of distance learning isn't new. Students have been completing correspondence courses by mail for over a century and more recently, universities have offered courses delivered via television and CD-ROMs. However, the web-based courses that emerged in the 1990's provide a faster and more complete method of delivering instruction (Bennett, 2008). These courses allow students the convenience of earning credit without actually leaving home. Students in internet-based courses can attend webcast lectures, participate in class discussions, and communicate with both professors and classmates regardless of geographic location.

Technology is playing a vital role in higher education. According to Educational Marketer (2003), online instruction is the fastest growing segment in higher education. As of 2003, 81\% of higher education institutions were offering at least one fully online or blended course (Educational Marketer, 2003). Indeed, Budden, Anthony, Budden and Jones (2007) mention that internet usage is increasing faster among college students than the general population. As of 2005, an estimated 1.1 million people were enrolled in online programs in the U.S. and online teaching was already a $\$ 7$ billion industry at the college level (Hechinger and Golden, 2005).

By the fall of 2006, almost 3.5 million students were taking at least one online course and online enrollments were continuing to grow at rates far faster than the higher education student population (Neal, 2008). This seems logical considering 49\% of undergraduates entering college are nontraditional students (Neal, 2008). Nontraditional students, many of whom work full-time and have family obligations sometimes have difficulty conforming to the traditional college schedule. According to the eLearners web site, the number of higher education institutions dedicated solely to distance learning instruction has grown to over 86 colleges and universities (Braun, 2008). These institutions recognize the growth of the adult student population and are attempting to capture some of this previously under-tapped market with online course offerings.

\section{OBJECTIVES}

This study examines student perceptions of internet-based courses compared to traditional classroom-based courses and investigates the means of maintaining student satisfaction with online learning. Specifically, this study focused on investigating the following:

- $\quad$ Primary reasons college students enroll in internet-based courses 
- $\quad$ The perceived quality of internet-based courses as compared to the quality of education delivered through the traditional classroom-based course

- $\quad$ The preferred structure for internet-based courses. This objective is addressed by analyzing the preference of delivery format (i.e., percentage of a course that is taught online) and a discussion of the learning tools students would like to see incorporated into the online learning experience.

\section{METHODOLOGY}

A questionnaire was developed to gather information from students who have taken full or partial internet courses. The questionnaire consisted of demographic questions, as well as questions regarding students' opinions and delivery preferences of internet courses. Two open-ended questions were also included to give respondents the opportunity to make suggestions for improving online learning and to identify classes they felt should not be taught in internet-format. The questionnaires were pre-tested, which resulted in a couple of minor changes. "Don't know" was added as a possible answer to a question concerning grade point average. Also, "didn't know it was an internet course" and "wanted the specific teacher" were added as potential responses to the question of why students took internet courses.

It should be noted that this study was limited to a convenient sampling of 470 undergraduate and graduate students attending a public university in the Southeast U.S. with an approximate enrollment of 15,000 students. Another limitation was that the questionnaires were distributed and collected during one week in the beginning of the spring semester. It is possible that some questionnaires were completed by students who may have been taking their first internet-based course. Lastly, the surveys were not given to a random sampling of students from every college at the university. Instead, questionnaires were collected from students in the colleges of Business, Education and Human Development, and Nursing and Health Sciences.

\section{FINDINGS}

For the objective of determining primary reasons for enrolling in internet-based courses, students were asked to indicate factors which impacted their decision in choosing internet courses over traditional classroom-based courses. Of the 470 students responding, Graph 1 shows that $61 \%$ cited work obligations (needed a flexible schedule), as a primary reason the course was chosen. Interestingly enough, of the students citing work obligations, only 35\% reported being employed full-time. Fifty-eight percent said they were employed part-time while 7\% were not currently employed. Contrary to the idea that online instruction is mostly for people who can't attend traditional classes because they work full-time, the majority of students citing work obligations as a primary reason for taking web-based courses were not employed full-time.

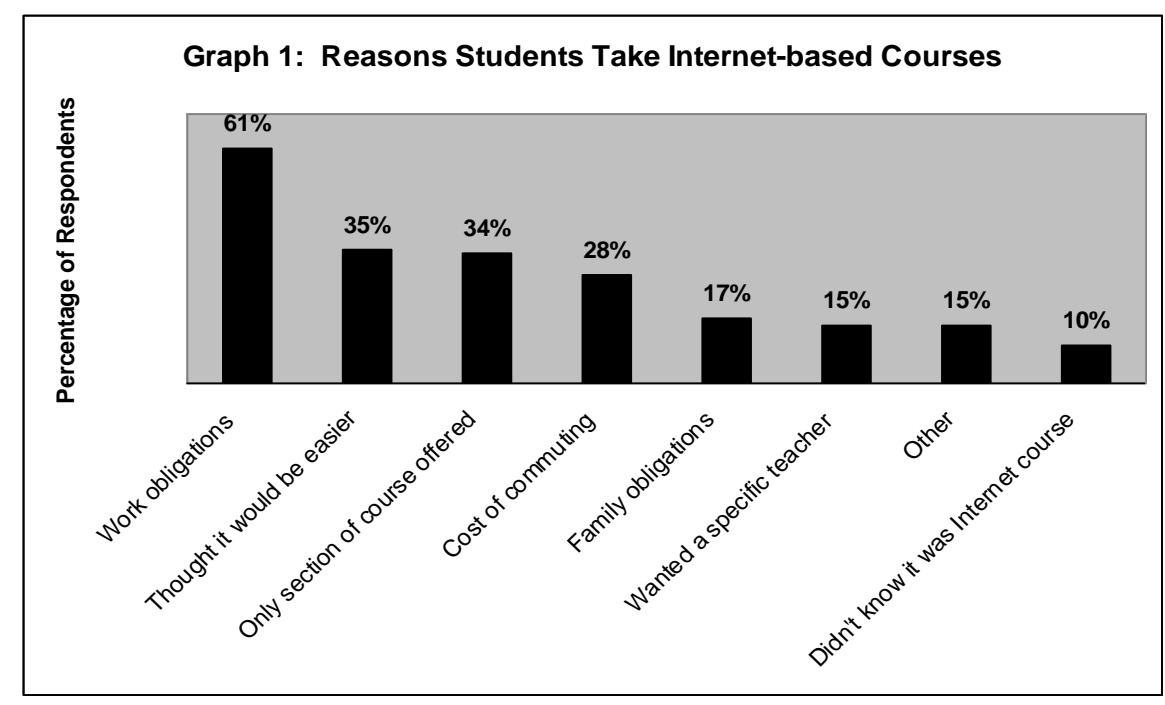

Note: Respondents were allowed to select multiple reasons. 
Following work obligations, students' reasons for enrolling in internet courses ranked as follows: $35 \%$ thought it would be easier than a traditional lecture course, 34\% stated it was the only section of the course offered, $28 \%$ cited the cost of commuting, $17 \%$ reported family obligations, $15 \%$ wanted the teacher who was teaching the course, $15 \%$ cited other reasons, and $10 \%$ were not aware they were choosing an internet course when they enrolled in it. This study supports the belief that students who have family obligations and are employees face challenges of conforming to the traditional classroom environment.

Of the respondents who stated family obligations were a factor in their decision to enroll in an internetbased course, $41 \%$ were enrolled as part-time students and 59\% were enrolled as full-time students. This indicates that full-time students desire an alternative means of course delivery to maintain full-time status while completing academic course work and fulfilling outside obligations. The most frequent "other" reasons listed by respondents for taking web-based courses were: "required course for major," "wanted to work at my own pace," "less time spent at school," and "flexible studying time." It was interesting to note that $10 \%$ of respondents enrolled in an internetbased course by accident.

The second objective, determining if online courses offer the same perceived quality of education as traditional classroom-based courses, was addressed by survey questions regarding students' overall satisfaction with internet-based courses, level of difficulty of internet-based courses, and whether cheating is perceived a common practice in internet-based courses. The students' satisfaction level was measured through the use of a five-point scale: very satisfied, somewhat satisfied, no opinion, somewhat dissatisfied, and very dissatisfied. Of the students surveyed, $42 \%$ indicated they were very satisfied with the internet course, $40 \%$ were somewhat satisfied, $10 \%$ had no opinion, $7 \%$ were somewhat dissatisfied, and $1 \%$ were very dissatisfied. (Graph 2)

Regarding the perceived difficulty level of internet-based courses, the measures were: easier than a lecture course, about the same as a lecture course and harder than a lecture course. (Graph 3) Results from the survey indicated $25 \%$ of students felt the internet-based course was easier than a lecture course, $59 \%$ felt it was about the same as a lecture course, and 16\% felt it was harder than a lecture course. The question concerning cheating on exams was measured as follows: cheating is widespread, happens sometimes but not often, and almost never happens. Of the students surveyed, $25 \%$ felt cheating is widespread, $59 \%$ felt cheating happens sometimes but not often, while $16 \%$ believed cheating almost never happens. (Graph 4)

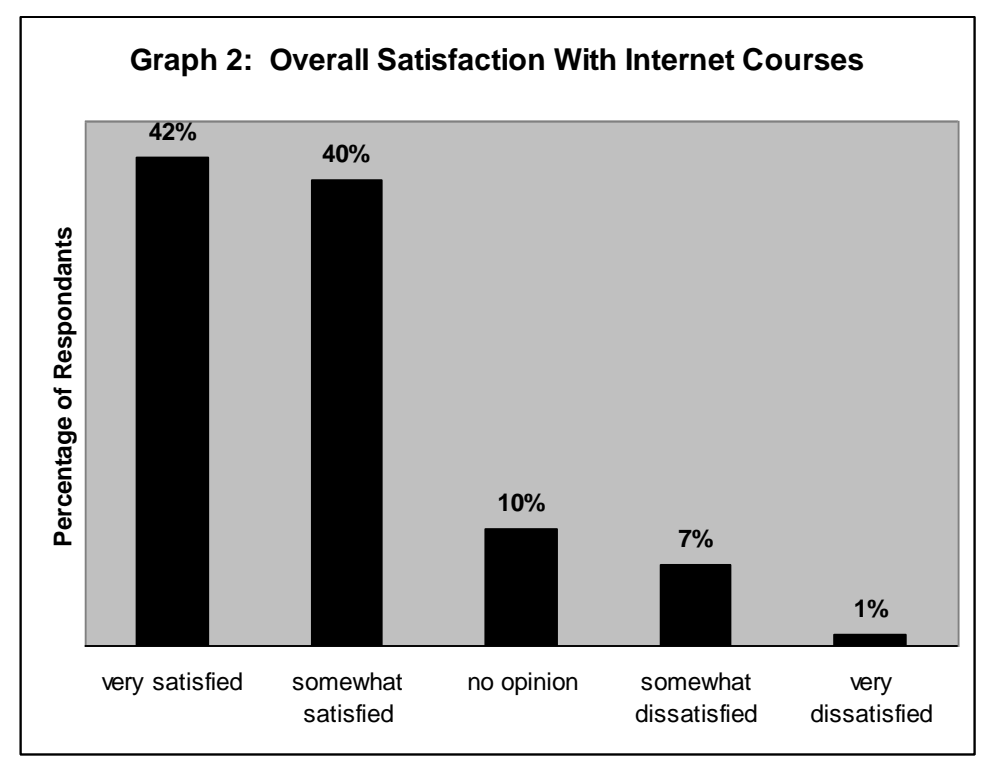


The satisfaction level with internet-based courses correlated with several of the reasons indicated for choosing to enroll in an online course. Based on the survey responses of the students who cited work obligations as a primary factor in choosing an internet-based course, $86 \%$ were very satisfied or somewhat satisfied with the course. Only $14 \%$ of these students had no opinion or were dissatisfied with the course. Students with family obligations were $57 \%$ satisfied or somewhat satisfied with the course and $13 \%$ had no opinion or were dissatisfied. Out of the students who factored cost of commuting as a reason to enroll in an internet-based course, $89 \%$ were satisfied or somewhat satisfied with the course. Only $11 \%$ of these students had no opinion or were dissatisfied with the online course. These high percentages of satisfaction indicate a positive response from students who have outside responsibilities and their satisfaction level with the internet-based courses.
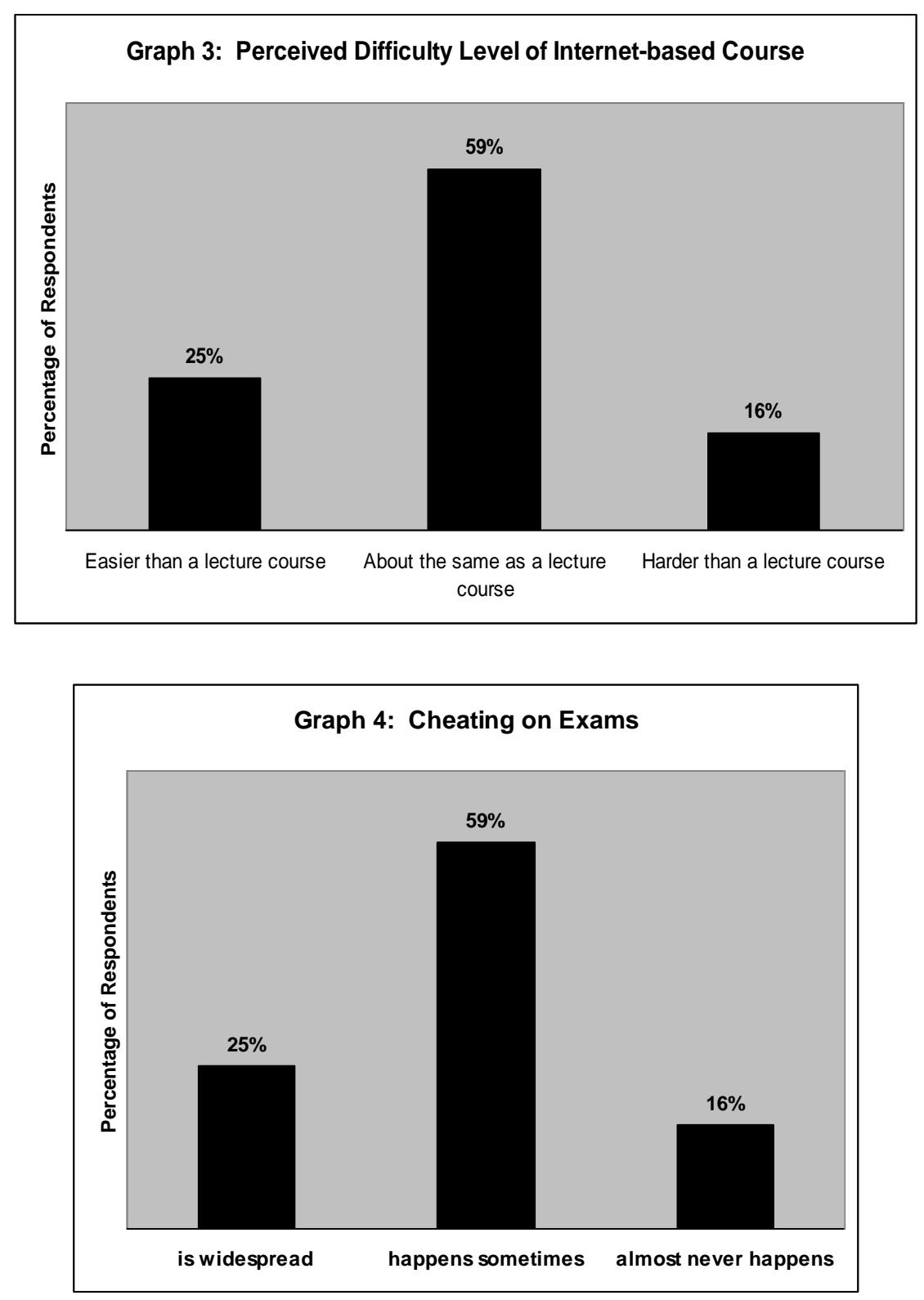

Interestingly enough, respondents had the same level of agreement regarding difficulty level and whether cheating occurs in internet-based courses. Based on the data collected, $84 \%$ of the students perceived the difficulty 
level of the internet course to be about the same or easier than a lecture course. Additionally, the data also showed $84 \%$ of the students think cheating occurs some of the time or is widespread in web-based courses. This could indicate that the perceived difficulty level of internet-based courses is related to the belief that cheating is widespread or at least occurs some of the time.

The third objective, determining the preferred structure for internet-based courses was addressed by two survey questions. The first question required respondents to indicate their preference for the percentage (or portion) of the class that should be online. The other question asked respondents to indicate which of three suggested online learning tools they felt would be most useful in an internet-based course. The respondents were allowed to mark "other" and to list their own recommendations for learning tools that could be used to enhance the virtual classroom. In the survey, the students were questioned on preference of delivery format for web-based courses. As illustrated in Graph 5, 38\% of students stated they would prefer a 100\% internet course, meaning the course would be taught completely by internet and there would be no face-to-face meetings. Twenty-nine percent of the students indicated they would prefer 50\% internet delivery, with half of the material being taught online and the other half taught in a classroom. The next most popular choice, indicated by $11 \%$ of the students, was $90 \%$ internet delivery, in which only the exams are given in a classroom environment. Eight percent of the students preferred $75 \%$ internet delivery; with a small portion of the course taught in a lecture classroom environment. Finally, $6 \%$ of the students preferred $33 \%$ internet delivery with the other $66 \%$ of the course to be taught in a lecture format.

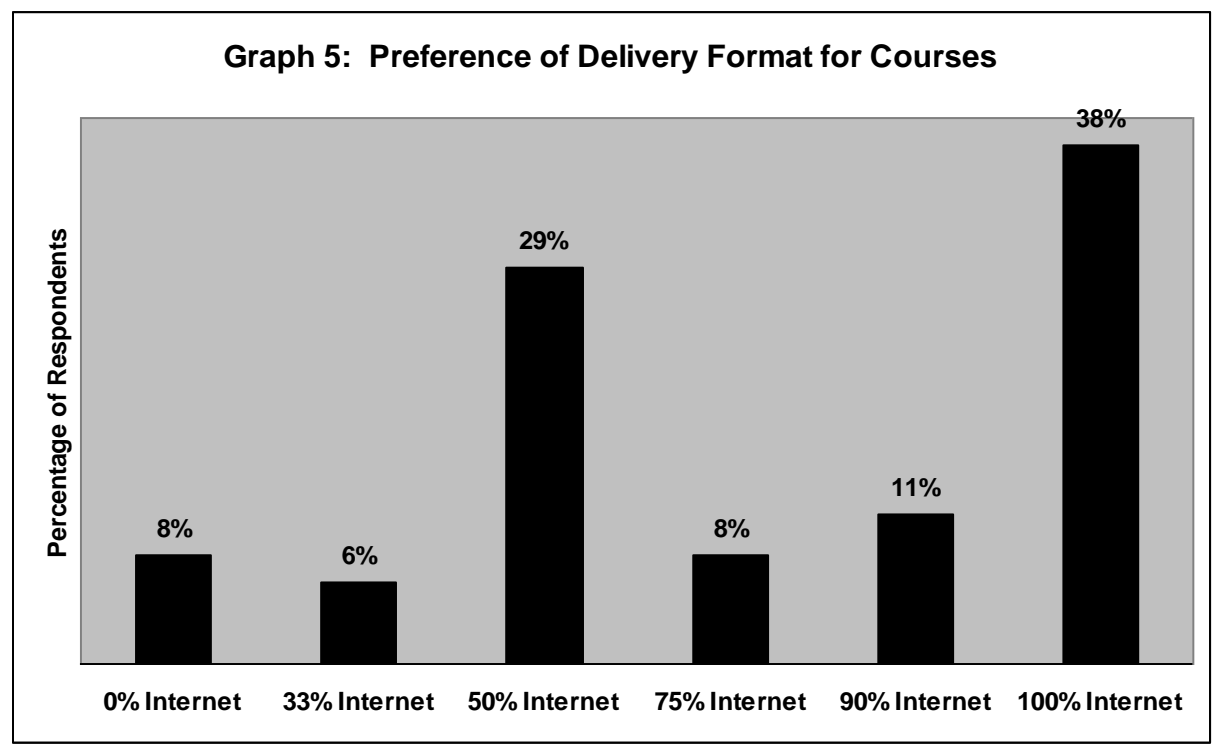

In these findings, employment status had an impact on preference of delivery for internet-based courses. Of the students who are employed full-time, $44 \%$ preferred a $100 \%$ internet delivered course. Following, $26 \%$ of these employed students chose 50\% internet delivery and the remainder of the course to be held in the traditional lecture environment.

The second part of the third objective concerned learning tools students would like to see incorporated into the internet course experience. Students were allowed to select as many tools as they would like to see incorporated into the internet classroom. In addition, there was an open-ended option for suggestions which were not listed. Of the various choices, the addition of tutorials (extra information on the topic for a better understanding) was selected $70 \%$ of the time-making it the most desired addition students would like to see incorporated into internet-based courses. Pre-recorded video lectures from the professor (just click and watch) was chosen by 59\% of the respondents, followed by cyber-labs (software enabling students to work hands-on with problems and view how they are worked out) by $56 \%$ of the surveyed students. (Graph 6 ) 
Students desire additional features that could be incorporated into internet-based classrooms. Additional supplements (pre-recorded video lectures and cyber-labs) may fulfill what is missing from the internet course-the advantages of physically being in a traditional lecture environment along with the professor. Some of the suggestions students offered were: live chat rooms with instructors, involvement of other professors from different countries, interactive discussion boards, freedom of software choices, links to other web-sites, and a virtual classroom environment.

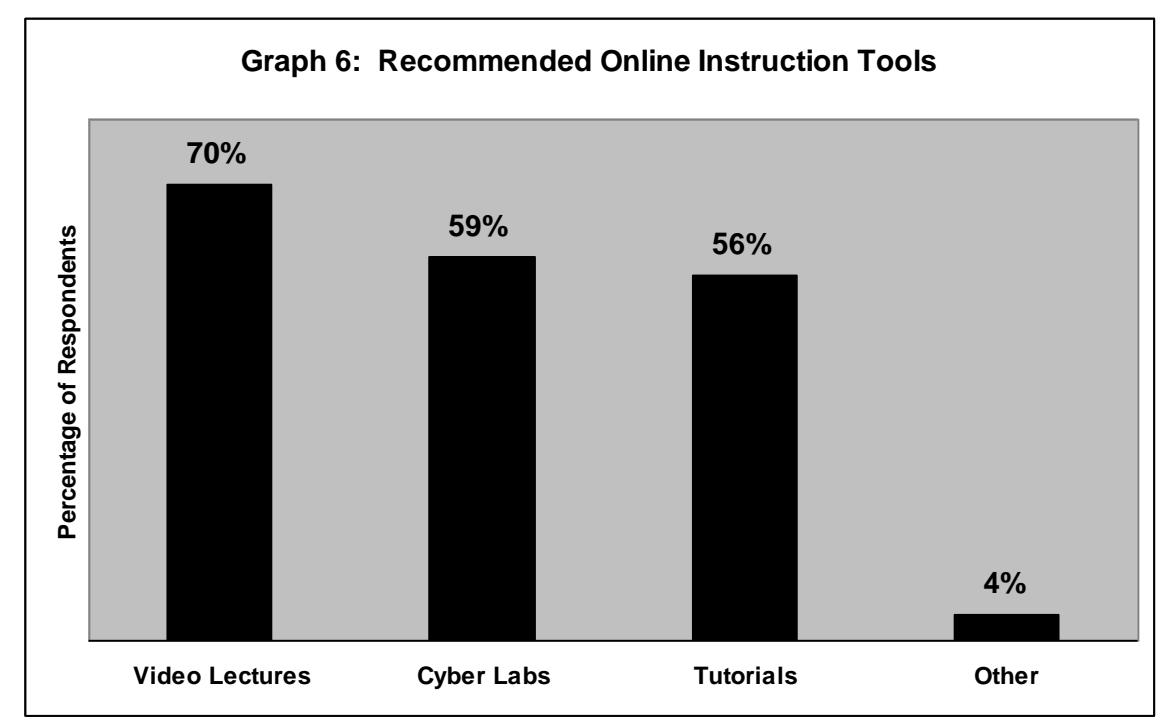

Note: Respondents were allowed to select multiple tools.

\section{CONCLUSION}

Online classes provide many advantages for both students and the colleges and universities that offer such courses. Less money is spent on travel since class attendance is often not required or is optional. Time that would otherwise be spent commuting to class can instead be spent working on assignments and studying or fulfilling work and family obligations. Also, many students like having the ability to work at their own pace and having the extra time to formulate answers to discussion questions and other assignments. Chamberlain, as cited in Beard, Harper, and Riley (2004), stated that students' inhibitions can actually be reduced by removing psychological or social barriers existing between student and teacher. In online class discussions, students have the opportunity to think at a deeper level, as opposed to typical classroom discussion situations in which students might be more hesitant to participate and express their thoughts (Braun, 2008).

Additionally, more seats are often available in classes taught by distance education, which tends to reduce the concern that some students have regarding course closure due to high enrollment. By utilizing and further developing online instruction, colleges and universities may be able to capitalize on emerging market opportunities and, at the same time, lessen capacity constraints on enrollment which could help to offset limited public education funding (Becker and Haugen, 2004).

Another advantage of online learning was clearly illustrated in the wake of Hurricane Katrina. Thousands of university students in Louisiana and Mississippi were displaced and left with few options for completing the courses in which they were enrolled. Some of these students were able to enroll in online courses and were able to continue their education. Unfortunately, many others suffered academic setbacks that resulted in delayed graduation dates that kept them from joining the workforce and contributing to society sooner (Braun, 2008). 
Web-based learning can provide a window of opportunity for many people who would not otherwise be able to attend classes at a college or university campus. Online instruction may be a means for students to complete their degree requirements faster which could mean they would be ready to enter the workforce that much sooner. In this regard, online instruction could benefit industries which are currently experiencing shortages of employees, such as nursing and education, by preparing students to fill vacancies in those career fields faster than traditional classroom-based teaching.

While there are many advantages to online instruction, disadvantages also exist. Some opponents of internet-based courses believe the resources necessary to further develop and improve traditional classroom-based courses will be depleted by the money and manpower used to create and deliver online courses (Braun, 2008). Few programs that are $100 \%$ online offer services common to most traditional universities such as job placement, internships, or counseling (Bennett, 2000). Critics of online instruction cite problems related to privacy issues, technological difficulties, and a focus on technology rather than on content in some situations. There are also fears that faculty members could be forced to teach course content with which they are unfamiliar, intellectual property rights could possibly be violated, and vendors who work with online course software will begin to control the curriculum (Braun, 2008).

Researchers have cited a lack of interaction with professors and other students as one of the disadvantages of online instruction. This problem may be exacerbated if instructors fail to utilize elements of online software packages that provide opportunities for student interaction with other students (Braun, 2008). High-quality online instruction requires at least as much, if not more, planning and student-faculty interaction as a traditional course taught in a classroom. Incorporation of new technologies is extremely important in delivering a quality learning experience in internet-based courses and there are many tools available for instructors today. However, faculty with demanding teaching, research and service schedules sometimes find it difficult to keep pace with technology (Zelin II and Baird, 2007). Ensuring faculty members are properly prepared to teach online courses is big hurdle for many institutions. For faculty who are willing and can find the time to learn, there are many new tools available.

Blackboard, Web CT, Desire2Learn are course management systems (CMS) which are commonly used by universities to add convenience and content delivery options. For example, Blackboard allows instructors to post announcements, assignments, course documents, lecture notes, PowerPoint presentations, lecture videos, and faculty credentials in a central place easily accessed by students. Means of direct communication include email, discussion boards, and real-time chats. Wireless technology is considered to be one of the latest advancements in online learning. Wireless technologies provide both instructors and students the ability to access internet courses anytime, anywhere, eliminating the physical separation of the instructor and student while permitting mobility to both (Becker and Haugen, 2004).

Due to the availability of computers and email, a communications revolution has taken place which has impacted the interaction between faculty and students (Pena-Sanchez and Hicks, 2007). A lack of interaction might be a problem for those seeking a more traditional college experience. However, for non-traditional students and students with disabilities, online learning can be ideal. Mature learners seem to be particularly well-suited to webbased instruction, a fact that should be noted by universities and colleges seeking to expand their student base (Bennett, 2000). Whether they are traditional or nontraditional, the same skills are required for online learning. Students undertaking internet-based courses should possess strong technological skills, as well as excellent reading and writing skills. Ready access to a good computer and an internet connection is also obviously very important. Above all, online students must possess a high degree of self-reliance, responsibility, and self-discipline (Deming, 2000).

In the future, colleges and universities seeking to implement online instruction, whether $100 \%$ online programs or hybrid courses, will probably want to focus on either a cost leadership or differentiation strategy to gain a competitive advantage. Those institutions that have a high regard for quality education, will probably choose the latter. By making their "product" different in the mind of the customer, they can attract more students and increase enrollment figures. While education is a business, it is important to remember that the focus in online education should remain on the content of the courses. 


\section{REFERENCES}

1. Becker, D., Haugen, S. (2004). Wireless Instruction: A New Dimension in Course Delivery. Management Accounting Quarterly, Fall 2004, Vol. 6, No. 1, p41-46.

2. Beard, L.A., Harper, C., Riley G. (2004). Online Versus On-Campus Instruction: Student Attitudes \& Perceptions. TechTrends, Volume 48, Number 6, p29.

3. Bennett, J. (2000). The Best Way To Take Classes. The Wall Street Journal, Nov. 27, 2000, pR.36.

4. Braun, T. (2008). Making a Choice: The Perceptions and Attitudes of Online Graduate Students. Journal of Technology and Teacher Education, Vol. 16, Iss. 1, p63.

5. Budden, C., Anthony, J., Budden, M. and Jones, M (2007). Managing the Evolution of a Revolution: Marketing Implications of Internet Media Usage Among College Students. College Teaching Methods and Styles Journal, Vol. 3, No. 3, p5-10.

6. Clark, K. (2008). New Answers for E-Learning. U.S. News \& World Report, 1/21/08, Vol. 144 Issue 2, p46-49, 3p, 1c.

7. Deming, L.H. (2000). Distance Learning: One Student's Perspective. Intercom, Jul/Aug 2000, Vol. 47 Issue 7, p18.

8. Educational Marketer (2003). Enrollment Blossoms in the Ivied Online Post-Secondary Space. 10/20/2003, Vol. 34 Issue 30, p4.

9. Hechinger, J. and Golden, D. (2005). In Katrina's Wake: Displaced Students Turn to Internet. The Wall Street Journal, A.12.

10. Hirschheim, R. (2005). The Internet-Based Education Bandwagon: Look Before You Leap. Communications of the ACM, July 2005, Vol. 48, No. 7, p97-101.

11. Neal, A. (2008). The Back-to-School Boom. The Saturday Evening Post, Indianapolis: Mar/Apr 2008, Vol. 280, Iss. 2, p72.

12. Pena-Sanchez, R. and Hicks, R. (2007). Student and Faculty Perceptions of Communication Channels: A Comparison of Survey Results. College Teaching Methods and Styles Journal, Vol. 3, No. 3, p25-40.

13. Zelin II, R. and Baird, J. (2007). Training Faculty to Use Technology in the Classroom. College Teaching Methods and Styles Journal, Vol. 3, No. 3, p41-48. 